\title{
ENTREVISTA COM IRENE MOUTINHO E SÍLVIA ELEUTÉRIO
}

\section{MARCELO DIEGO}

Universidade Federal do Rio de Janeiro

Rio de Janeiro, Rio de Janeiro, Brasil

Resumo: Nesta entrevista, Irene Moutinho e Sílvia Eleutério, pesquisadoras responsáveis pela edição da Correspondência de Machado de Assis, em cinco tomos, sob a direção de Sergio Paulo Rouanet, contam como se envolveram com a iniciativa; descrevem o método de trabalho que adotaram; comentam os critérios que utilizaram; e compartilham análises e impressões desse material, a que tiveram acesso em primeira mão.

Palavras-chave: correspondência; crítica textual; vida literária.

\section{INTERVIEW WITH IRENE MOUTINHO AND SÍLVIA ELEUTÉRIO}

Abstract: In this interview, Irene Moutinho and Silvia Eleutério, the researchers responsible for the edition of the Letters of Machado de Assis, in five volumes, directed by Sergio Paulo Rouanet, tell how they got involved in the initiative; describe their working method; comment the criteria adopted; and share their analysis and impressions of the material they had access to in first hand.

Keywords:letters; textual criticism; literary life. 


\section{Apresentação}

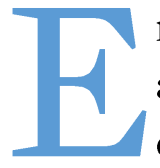

m 1908, poucos meses antes de seu falecimento, Machado de Assis autorizou a reunião e edição de suas cartas, ainda que bastante cético quanto ao interesse que esses escritos de origem privada poderiam ter para a recepção pública. No entanto, foi apenas na década de 1920 que surgiram as primeiras iniciativas de publicação da correspondência do escritor, as quais se multiplicariam ao longo do século $\mathrm{XX}$, todas de extremo interesse e mérito, embora sempre parciais e, muitas vezes, inconsistentes. Foi apenas no início do século XXI, tendo em vista a celebração do centenário de morte de seu presidente de honra, que a Academia Brasileira de Letras resolveu levar a cabo o projeto de publicação do epistolário mais abrangente e rigoroso possível de Machado de Assis. O resultado foi a monumental Correspondência de Machado de Assis, em cinco tomos, dada a público entre 2008 e 2015, reunida, organizada e comentada por Irene Moutinho e Sílvia Eleutério, sob a coordenação e orientação de Sergio Paulo Rouanet.

Desde que começou a ser publicada, a Correspondência de Machado de Assis vem instigando e subsidiando a crítica machadiana; exemplo disso são os artigos "Epistolografia de Machado de Assis: escrita de si e testemunhos de criação literária", de Marcos Antonio de Moraes, e "Anotações sobre a correspondência de Machado de Assis", de Antônio Dimas, publicados nesta Machado de Assis em linha. Moraes assinala a postura reticente da primeira geração de estudiosos do escritor, em relação àquilo que se conhecia da sua correspondência:

O crítico Augusto Meyer, em 1935, e a biógrafa Lúcia Miguel Pereira, em 1936, depreciaram a epistolografia de Machado de Assis, ao contrastá-la com a sua produção literária. Augusto Meyer supõe que os escritores de ficção "se confessam através das encarnações imaginárias, indiretamente, com uma sinceridade mais honesta do que na correspondência ou nos cadernos íntimos"; confirma a hipótese com "a correspondência de Machado de Assis [que] é um modelo de discreta insignificância". Lúcia Miguel Pereira vê um "abismo" entre o romancista "dissecador de almas" e o "espírito trivial" que se manifestava nas "atitudes do grande escritor" e na correspondência. A literatura, para ela, então, era a estrada real para o conhecimento do "verdadeiro Machado"; a carta apenas refletia "o convencionalismo dos gestos". (MORAES, 2011, p. 96) 
Nesse sentido, o rigor da pesquisa e da edição da Correspondência de Machado de Assis teve como resultado não apenas a disponibilização de uma importante fonte primária, mas também a definitiva legitimação dessa fonte. Comenta Dimas:

Da massa formidável dos cinco volumes de cartas - anotadas pela competência técnica de Irene Moutinho e de Sílvia Eleutério, soba a coordenação de Sergio Paulo Rouanet - emergem outros Machados. Alguns deles arranham a imagem canônica que a crítica consolidada construiu, consagrou, repassou e sustenta até hoje diante dos leitores brasileiros, diletantes ou profissionais. Por causa desse maço de cartas, deram-se acréscimos, extensões, confirmações, variações, desmentidos ou negações daquele Machado que nossa crítica literária ergueu logo antes e depois da morte desse "menos enfático dos nossos escritores", segundo Rouanet. (DIMAS, 2017, p. 159)

Em seu gênero e escopo, a edição da Correspondência de Machado de Assis é uma empreitada insuperada e sem par no Brasil. Na entrevista que se segue, Irene Moutinho e Sílvia Eleutério contam como se envolveram com essa iniciativa do embaixador e acadêmico Sergio Paulo Rouanet, descrevem o método de trabalho que adotaram, comentam sobre os critérios que utilizaram e compartilham suas análises e impressões do conjunto vastíssimo de cartas com o qual tiveram o privilégio de conviver, intimamente e em primeira mão. Irene Moutinho respondeu ao vivo às questões propostas pela Machado de Assis em linha, em 14 de janeiro de 2020, e Sílvia Eleutério respondeu por escrito a essas mesmas questões, em 04 de fevereiro de 2020; para a conveniência do leitor, as respostas das duas entrevistadas a cada uma das questões foram dispostas em sequência, conformando uma única entrevista.

Sobre as entrevistadas: Irene Moutinho, escritora, tradutora e pesquisadora, colaboradora e coordenadora do Índice da Enciclopédia Mirador Internacional; pianista formada pelo Conservatório Brasileiro de Música onde fez pós-graduação em musicologia, possui experiência como preparadora de texto e coordenadora editorial, bem como na área de gestão da cultura; desempenhou funções de assessoria, consultoria e coordenação na Funarte, entre 1979 e 1996, no Ministério da Cultura, na gestão de Antônio Houaiss, na Embratur e na Academia Brasileira de Letras. Sílvia Eleutério, autora e diretora teatral, possui um doutorado em Literatura Brasileira e outro em Língua Portuguesa, ambos pela Universidade Federal do Rio de Janeiro; 
coordenou ciclos de leitura dramatizada, realizou adaptações para o teatro de textos clássicos da literatura brasileira e roteiros de cinema premiados.

\section{Entrevista}

1. Como e quando se deu o convite para participar do projeto de edição da correspondência de Machado de Assis? Vocês já haviam trabalhado com textos do escritor antes?

Irene Moutinho: Eu estava na Academia Brasileira de Letras desde 2001, chefiando o Centro de Memória, com inúmeras atribuições, o que foi uma coisa muito boa, um trabalho muito grande, e já era amiga do Sergio Paulo Rouanet desde os anos 1990. Conhecendo bem o Arquivo da Academia, o Rouanet veio até mim com essa ideia e fiquei entusiasmada por ela. Isso aconteceu em 2005, fazia quatro anos que eu estava lá. Eu era já apaixonada por Machado - ninguém pode deixar de sê-lo -, já tinha lido muito Machado, mas essa foi uma entrada muito mais intensa, de coração mesmo, na obra dele. Fomos planejando a edição, e desde o início a ideia já era que ela saísse a partir de 2008, ano do centenário de morte.

O Rouanet tinha uma visão estupenda, que era fazer a edição cronológica da correspondência, em vez de por correspondente, dialogal. Como grande conhecedor do século XVIII, ele estava bastante familiarizado com a monumental correspondência de Voltaire, que foi feita por uma equipe gigantesca, Europa afora, e que era cronológica, não era bilateral. Hoje eu estou conversando com você, e é isso; amanhã posso estar conversando com outra pessoa; e depois de amanhã posso estar conversando com você novamente. Eu noto que às vezes cartas de uma mesma data, que o Machado recebeu ou escreveu no mesmo dia, dão diapasões de leitura completamente diferentes: uma pode ser formal, outra, um bilhetinho de intimidade. A abordagem cronológica tem essa riqueza, a de reconstruir um pouco a biografia.

Como ponto de partida, havia a correspondência ativa e passiva conservada no Arquivo da Academia. Então comecei a me calçar, fui fazendo um levantamento, listando tudo quanto é carta de ou para Machado que já se conhecia, que estava aqui, que estava acolá, nos diversos epistolários, e com a perspectiva de mergulhar fundo na pesquisa em outros arquivos, nas biografias, na bibliografia. Cheguei, nesse primeiro momento, a umas seiscentas e poucas - e chegaríamos, ao fim, a 1.179. Quando o plano de 
trabalho foi se armando, vi que era necessário mais alguém, mas não mais muita gente, para não misturar muitas cabeças, muitos critérios. Foi então que Sílvia Eleutério entrou; eu a conhecia pouco, mas ela havia feito Letras, tinha uma tese sobre Machado, havia escrito uma peça para crianças, $O$ baú do Seu Machado, e estava coordenando um projeto de teatro para estudantes na Academia. Falei com o Rouanet, que concordou plenamente, conversou com ela, e eu fiz a carta para o Marcos Vilaça, que era então Presidente, propondo que Sílvia viesse trabalhar conosco. Ele aceitou e nós passamos a trabalhar juntas, mas apenas as duas, sozinhas.

Claro que havia um suporte no Arquivo e na Biblioteca, porém pequenas tentativas de pedir a determinada pessoa que ajudasse em determinado caso, não prosperaram. Em 2007, acompanhando o Presidente a uma visita ao teatro da Academia, que estava em obras, caí de uma altura de dois metros. Não quebrei nada, mas fiquei muito debilitada, muito abalada, e concluí que não ia ficar mais lá, na Academia, de forma fixa. O presidente Vilaça concordou, e a partir de então eu e a Sílvia fomos contratadas de forma independente, para esse projeto. Em 2008 saiu o primeiro volume, que nós fizemos em conjunto, e a experiência com ele, a aprendizagem que ele nos trouxe, mostrou que era melhor dividir as tarefas, em vez de ficarmos as duas trabalhando com as mesmas cartas. Falamos com o Rouanet e ele concordou inteiramente.

A essa altura, a relação dos correspondentes já estava praticamente completa, de modo que pudemos fazer essa divisão, cada uma ficou com determinado número de correspondentes, com um peso igual de cartas, o que foi bom, também, para cada uma ficar mais especializada nos seus correspondentes e na relação deles com Machado. É claro que nós cruzávamos as cartas, tínhamos rodadas em que uma revia o trabalho da outra. Só que ela mora na Tijuca, eu em Botafogo, cada qual com os seus compromissos, e por isso começamos a fazer uma coisa muito boa: ela ia muito para São João delRei, tinha família lá, eu tinha ido apenas uma vez, de passagem; e começamos a ir para lá, por períodos, para ficar em uma pousada, bem instaladas, trabalhando juntas. Cada uma tinha a sua vida, o seu ritmo, mas no momento em que nos sentávamos para trabalhar, era full time. Era muito importante a leitura mútua, a discussão sobre as cartas e sobre as notas. No entanto, todas as notas têm nossas iniciais, e isso foi fundamental. No primeiro tomo vemos algumas com "IM/SE", "Irene Moutinho e Sílvia Eleutério", e também "SPR", nas que foram feitas pelo Rouanet, mas, no trabalho como um todo, cada uma tinha o seu corpus, a sua tendência, a sua formação, olhava mais para uma coisa ou outra, e foi fundamental que essa autoria fosse preservada. 
Sílvia Eleutério: Em 2004, a convite do acadêmico Evanildo Bechara, comecei a dirigir o Ciclo de Leituras Dramatizadas da ABL, levando à cena autores considerados clássicos da dramaturgia brasileira, entre os quais Machado de Assis. Lá conheci Irene Moutinho, que chefiava o Centro de Memória e nos aproximamos em razão de muitos interesses em comum. O acadêmico Sergio Paulo Rouanet, àquela altura, era o diretor do Arquivo da ABL, do qual o Centro de Memória fazia parte.

Havia tempo Sergio desejava trazer à luz a correspondência de Machado guardada no Arquivo. A sua ideia era publicar em ordem cronológica tanto a correspondência ativa quanto passiva de Machado, buscando estabelecer o fluxo comunicativo. Não desprezaríamos nada, publicaríamos tanto as cartas reconhecidamente fundamentais, quanto as que à primeira vista parecessem triviais. Decidimos também reunir tudo quanto pudéssemos encontrar em outros arquivos e publicações. Vasculhamos toda a correspondência já publicada nas denominadas Obras Completas de Machado de Assis, nos epistolários parciais, nas biografias, livros etc., e percebemos que no acervo da ABL havia diversas cartas inéditas.

Sob a sua coordenação, Irene Moutinho e eu escrevemos um projeto com as linhas gerais da pesquisa e apresentamos, com a chancela do Sergio, ao presidente da casa Marcos Vilaça, com vistas ao ano de 2008, centenário da morte de Machado de Assis. Este projeto inicial foi ampliado e redefinido, constituindo o nosso arcabouço de pesquisa.

Minha tese de doutoramento, pela Faculdade de Letras da Universidade Federal do Rio de Janeiro, é sobre o escritor - Machado de Assis e a presença do analista, de 1995. De lá para cá aprofundei os meus estudos sobre o autor, me especializando. Participei de conferências e ciclos de estudos de temática machadiana. Em 2003, dirigi a montagem O baú do Seu Machado, no Teatro Raimundo Magalhães Jr., na ABL. Em 2008, publiquei em coautoria $O$ baú do Seu Machado, livro infanto-juvenil, cuja finalidade era apresentar o escritor às crianças e aos jovens. O livro faz parte do catálogo permanente do selo Nova Fronteira, da Ediouro.

Em 2003, doutorei-me na Faculdade de Letras da UFRJ, em Língua Portuguesa - A variação ter/haver: documentos notariais do século XVII. De 1995 em diante inseri sistematicamente os estudos diacrônicos, os de crítica textual, de ecdótica e de história da língua portuguesa em minha vida. Dediquei-me também ao ensino de Língua Portuguesa e Literatura Brasileira em diversas instituições de ensino. No Ciclo de Leituras Dramatizadas da 
$\mathrm{ABL}$, apresentando os clássicos do teatro brasileiro do século XIX e início do XX, Machado dramaturgo tornou-se um autor regularmente lido. Estabelecemos como finalidade apresentá-lo sistematicamente às novas gerações que constituíam o público das leituras.

2. Antes do trabalho de edição, propriamente dito, o projeto da correspondência demandou um trabalho grande de pesquisa. Como vocês conjugaram essas duas tarefas? Em linhas gerais, qual foi a metodologia de trabalho adotada?

Irene Moutinho: A pesquisa se deu pari passu ao trabalho de edição. Eu havia feito um levantamento, partindo do imenso acervo machadiano do Arquivo e dos principais epistolários, mas novas cartas vieram à tona enquanto já editávamos as primeiras. Pesquisamos na Biblioteca Lúcio de Mendonça da Academia, na Biblioteca Nacional, no Instituto Histórico e Geográfico Brasileiro, no Arquivo Histórico do Itamaraty, no Real Gabinete Português de Leitura, na Fundação Casa de Rui Barbosa, no Museu da República, na Fundação Joaquim Nabuco, em muitos lugares. O achado de novidades foi modesto, porque a correspondência de Machado de Assis é um tema que já foi muito investigado. Mas foram aparecendo algumas coisas, inéditas e por isso empolgantes. Já estava fechado o quinto tomo, por exemplo, quando eu descobri uma cartinha do Medeiros de Albuquerque, que aliás não era uma figura muito querida do Machado, mas que era inédita.

Outro caso interessante foi o do José Veríssimo. Eu tive a oportunidade de fazer o contato com uma nora de um filho do Veríssimo, amiga da Rachel Jardim, uma senhora simpaticíssima, Helena Veríssimo. O marido ainda estava vivo e tinha ficado com o arquivo do avô, em um apartamento em Copacabana; ele sabia o que era, mas mantinha fechado a sete chaves. Depois que ele faleceu, a Helena me chamou e eu fui lá. Eu nunca tinha visto os originais das cartas do Machado; o epistolário Machado-Veríssimo saiu na Revista da Academia, em 1929-1930, e as cartas do Veríssimo, o Machado guardava todas, mas e as originais do Machado, onde estariam? Quando as encontrei, tive febre. Transcrevi tudo, e depois a Helena fez a doação para a Academia, mas há cinco ou seis, rigorosamente inéditas, que ficaram prontas depois de sair o quinto tomo, e ainda não sei se vão sair em uma nova edição, ou se vamos publicar de modo avulso, na Revista Brasileira. 
Sílvia Eleutério: Nosso ponto de partida foi o valioso Arquivo da ABL, cujo fundo arquivístico reúne os documentos produzidos e recebidos por Machado, ao longo de sua vida, a maioria manuscritos originais autógrafos, quase todos acumulados por ele ou doados à instituição. Tínhamos um começo auspicioso. A fortuna crítica machadiana nos deu muitas indicações de documentos e acervos a pesquisar. Digamos, por exemplo, que Raimundo Magalhães Júnior ou Lúcia Miguel Pereira citassem um trecho de carta ou fizessem menção a algum documento desconhecido, inseríamos na listagem. Havia também as referências nas próprias cartas. Um correspondente acusava o recebimento ou o envio de uma carta que não constava de nenhum acervo, inseríamos na listagem. Fomos fazendo uma grande teia de conexões. Estabelecemos um conjunto aberto a novas inserções e mantivemos esta perspectiva até o presente momento. A Correspondência é uma possibilidade em aberto, a qualquer momento pode surgir um novo documento.

Paralelamente, fizemos um levantamento das instituições brasileiras e estrangeiras que pudessem guardar algum documento. Exemplos de instituições brasileiras pesquisadas: Biblioteca Nacional, Fundação Casa de Rui, Real Gabinete Português de Leitura, Instituto Histórico Geográfico Brasileiro, Biblioteca Brasiliana Guita e José Mindlin, Biblioteca Mário de Andrade, Instituto Histórico e Geográfico de São Paulo, Instituto Histórico e Geográfico de São João del-Rei, Museu Mariano Procópio, Arquivo Histórico do Itamaraty, Fundação Joaquim Nabuco etc.; instituições europeias: Biblioteca de Lisboa, Ministério da Fazenda de Portugal, Universidade do Porto, Universidade de Braga, Biblioteca de Paris etc.; e norte-americanas: Biblioteca do Congresso Norte-Americano; The Oliveira Lima Library, da Universidade Católica de Washington.

Àquela altura, 2006-2008, algumas instituições brasileiras, como a BN, o Real Gabinete, o IHGB, Casa de Rui e o Arquivo Histórico do Itamaraty, ou não estavam com seus acervos inteiramente digitalizados ou só os tinham digitalizados parcialmente; por isso, muitos documentos precisaram ser pesquisados in loco. Trabalhamos muito com microfilmes. Depois, com o correr dos anos, os acervos digitalizados foram ampliados, o que nos facilitou muito. Tivemos também muitas contribuições espontâneas, pessoas que gentilmente nos cediam ou localizavam documentos. O acadêmico Alberto Venâncio Filho nos deu cópias digitalizadas de manuscritos originais e indicações de onde encontrar outros; José Mindlin também nos cedeu cópia de um manuscrito de Euclides da Cunha, Antônio Carlos Secchin, a Família 
Rodrigo Octavio, a Família Veríssimo e tantos outros, que temo ser injusta com quem não citei.

A nossa intenção era fazer uma publicação que alcançasse o público em geral: certamente especialistas, professores e estudantes, mas também pessoas interessadas em conhecer Machado de Assis. Não pretendíamos fazer um trabalho acadêmico stricto sensu. Então elaboramos uma edição visando o conforto do leitor, se se pode dizer isto. Optamos por fazer a atualização ortográfica, mas, ao mesmo tempo, buscando a maior fidelidade aos documentos que nos serviram de base, bem como optamos pelo mínimo de intervenções.

Tínhamos definido de saída a orientação pelo fluxo cronológico. Fizemos então a listagem do acervo do Arquivo da ABL, inserimos as referências a documentos depositados em outras instituições, pesquisamos as obras completas (Aguilar, Jackson etc.), os vários epistolários parciais, as biografias machadianas, as revistas, os catálogos e jornais antigos e recentes, e começamos a recolha dos documentos, definindo as tipologias (manuscritos originais, fac-símiles de manuscritos originais, transcrições de manuscritos originais, documentos impressos e fac-similados de jornais e revistas, digitalizações e microfilmes de jornais e revistas, originais impressos, edições princeps etc.). Essa parte foi bastante trabalhosa.

Além disso, tivemos que definir as categorias de documentos que entrariam na Correspondência, o que foi uma grande questão para nós. Por exemplo, já fazia parte da fortuna crítica machadiana as cartas abertas de e para José de Alencar, de 1868. Havíamos descoberto várias outras cartas abertas em jornais de época. O que fazer? Ignorá-las ou inseri-las? E as cartasprefácio? E os poemas de ocasião endereçados a amigos, a admiradores e a damas do tempo, e que seguiram aos receptores como carta, o que fazer? Telegramas, cartões de apresentação rapidamente escritos marcando um encontro ou pedindo algo, com data e assinatura, entrariam ou não? E os cartões-postais só com data e assinatura, sem qualquer outro texto? Definir isto foi muito importante. Decidimos também distribuir os correspondentes entre mim (SE) e Irene (IM), com cada uma responsável pelas notas de seus correspondentes. Isto facilitou enormemente nosso trabalho, o que não impediu de nos auxiliarmos mutuamente.

Distribuímos os períodos de atividade epistolar em cinco momentos, perfazendo inicialmente 48 anos: Tomo I (1860-1869); Tomo II (1870-1889); Tomo III (1890-1900); Tomo IV (1901-1904); Tomo V (1905-1908). Foi necessário depois elaborar os Cadernos Suplementares, pois algumas vezes o 
tomo do período já estava na gráfica rodando, quando nos chegavam às mãos novas cartas. Com isto, o período de atividade epistolar de Machado passou de 48 para 51 anos, já que encontramos documentos de 1857. Até o presente reunimos 1179 documentos, 270 correspondentes e produzimos 4518 notas.

3. Quais condições materiais e imateriais (institucionais, políticas, culturais) foram fundamentais para a realização desse projeto?

Irene Moutinho: Para esse trabalho, o empenho do Rouanet foi o ponto fundamental. Um apoio admirável, inclusive ao acolher tudo que nós propúnhamos, orientando e contribuindo imensamente, sem jamais se colocar de uma maneira superior, como se soubesse mais. Na Academia, ele obteve o apoio das diretorias. Eu e a Sílvia fomos contratadas para esse trabalho; em termos de um projeto para a Academia, e considerando o volume de trabalho, não se pode dizer que tenha sido nada nababesco, foi algo relativamente modesto, mas, àquela altura, essa não era a discussão, nós estávamos com um objetivo e com o coração. As instituições todas em que precisamos pesquisar, como a Casa Rui (o arquivo do Plínio Doyle foi ótimo, assim como coleções de periódicos que não encontramos em outros lugares), o Real Gabinete, o Museu da República, entre outros, nos receberam de portas abertas. Mas foi um trabalho muito intenso, nós éramos desde as pesquisadoras que decifram manuscritos e fac-símiles até as assistentes que penam horas em copiadoras; não tínhamos uma equipe, um estagiário, e não dava mesmo para incorporar, tinha que ser assim.

Sílvia Eleutério: Tivemos, a partir de 2007, o apoio irrestrito da Academia Brasileira de Letras, que nos forneceu meios financeiros e humanos, por sete anos. Abriu-nos o Arquivo, o Setor de Museologia, o Setor de Editoração, a Biblioteca Lúcio de Mendonça e Rodolfo Garcia, e tudo o mais necessário ao trabalho. Os funcionários desses setores foram excepcionais, nos facilitavam tudo que estivesse ao alcance deles. O trabalho do Sergio também foi fundamental, negociando com a Academia e as demais instituições a que desejássemos acesso; outras vezes sugerindo caminhos e meios, outras tantas nos tirando de impasses; e outras nos dando força para prosseguir.

Fazíamos reuniões mensais para resolver questões e acertar detalhes. No fechamento de um tomo, tínhamos de trabalhar juntas, então íamos para São João del-Rei por longos períodos, para concluir o material a ser entregue na 
gráfica. Era uma fase de trabalho árduo, diariamente das $8 \mathrm{~h}$ até 19-20h debruçadas sobre o material e livros e mais livros. Sergio habitualmente estava em Tiradentes. Então ali, na calma de Minas, a gente tomava decisões importantes, discutia pontos que restavam duvidosos e ultimava a edição. Nas horas de lazer que vez por outra fazíamos, conversávamos e ríamos muito.

4. Quais os principais dilemas que vocês, como editoras de textos de Machado de Assis, enfrentaram? Ou seja, quais os maiores desafios que o texto de Machado de Assis apresenta a quem queira editá-lo?

Irene Moutinho: Para começar, talvez o principal problema seja que originais, sobretudo os que foram para a Garnier desapareceram, salvo os de Esaú e Jacó e Memorial de Aires, que estão na Academia. Além disso, o Machado tinha uma maneira de rasurar (que parecia a maneira normal de o Veríssimo escrever, com uma letrinha que fica fazendo voltas, parece um arame farpado) que fazia com que não desse mesmo para entender o que estava embaixo. E tinha a pontuação, que era louca, e com isso eu me bati muito na edição da correspondência feita com base nos manuscritos ou em periódicos antigos. Ele usa não dois pontos, usa ponto e vírgula no lugar, sistematicamente, o que era uma coisa de época, porque noto isso também nos correspondentes e em outros autores.

Sílvia Eleutério: O cotejamento dos vários testemunhos de um mesmo documento para chegar o mais próximo do que teria sido escrito é, digamos, uma questão importante. Por exemplo, para a transcrição da famosa carta de José de Alencar, cujo original manuscrito provavelmente não existe mais, cotejei quatro variantes impressas do século XIX e uma do XX. Entre as cinco variantes, há diferenças substanciais, como por exemplo, a supressão de trechos; a alteração lexical com a troca de vocábulos ou de letras; a alteração da sintaxe de ordem; a inserção de frases e palavras, bem como a alteração na pontuação.

Outro dilema era a decifração de cartas com letras quase indecifráveis ou então a leitura de documentos muito deteriorados. Estabelecer o texto nessas condições é uma tarefa difícil. Você pode errar na leitura, pode ler o que não está ali, pode não ler. São muitas as vicissitudes. Mas ainda há outros dilemas: localizar fontes fidedignas para aquilo que está dito no texto e buscar informações sobre missivistas com quase nenhum rastro histórico. Tudo isto 
tendo de cumprir prazos. E last but not least, trabalhar com os fatos históricos sem pensamentos preconcebidos, sem atribuir valor a algo que foi dito por um missivista à luz do gosto pessoal ou da visão de mundo pela qual o pesquisador tenha simpatia.

Em resumo, os principais desafios foram: localizar e reunir os documentos; decifrar letras quase indecifráveis e ler documentos muito deteriorados a fim de estabelecer o texto; resolver as discrepâncias entre um mesmo documento e os diversos testemunhos; estabelecer uma taxionomia que abarque a documentação de forma clara e eficiente; delimitar o que entrará nas notas ou não; definindo o seu escopo e a relevância; e estabelecer textos de uma outra sincronia e estabelecer critérios para a edição que façam sentido para o leitor de hoje.

5. A esse respeito, a pontuação dos textos de Machado infringe regras hoje tomadas como inquestionáveis, como a que condena a separação de sujeito e predicado por vírgulas. Como vocês lidaram com as diferenças entre os usos de Machado e as regras atuais? Para vocês, quais seriam os limites para a atualização do texto de Machado?

Irene Moutinho: Nós tomamos uma decisão, que nos parece bastante válida, que foi a de colocar uma nota explicativa no início de cada tomo. A Sílvia trabalhou nisso muito bem, desde o primeiro tomo. A nota explica, por exemplo, o desenvolvimento das abreviaturas, que é sempre em itálico, as assinaturas, que não são desenvolvidas, porque os nomes aparecem sempre em cima etc. É a mesma nota, porque os critérios foram os mesmos ao longo de todo o trabalho. Ela diz:

A pontuação original foi respeitada, mesmo que pareça, ao olhar contemporâneo, um desvio da norma-padrão da língua portuguesa escrita no Brasil. Apenas no caso dos impressos, em que os equívocos foram claramente tipográficos, foram feitas alterações: o Teatro de São; Pedro / o Teatro de São Pedro. (ASSIS, 2009, p. 32).

Então essa vírgula entre o sujeito e o predicado foi mantida, e ela funcionava como uma respiração da frase, que você pode notar, aliás, em todos os autores dessa época, não é uma coisa do Machado, é uma coisa corrente. 
Sílvia Eleutério: A pontuação baseada na morfossintaxe (não se separa sujeito do predicado por vírgula, a não ser que haja algum elemento sintático interposto, tipo uma locução adverbial, um aposto etc.) é uma proposição mais claramente sistematizada a partir do século XX. O que vigorava ao tempo de Machado era um sistema híbrido, que misturava usos sintáticos, prescrições etimológicas e determinações impressionísticas, do tipo "o bom uso". A pontuação tinha e tem ainda um pé no ritmo da fala, a famosa pausa. A frase "Eu vou, sim.", escrita assim, ao tempo dele era usual, e não interpretada como pausa de reforço, por exemplo. A gramática normativa chancela esse uso; mas hoje, entre os falantes e leitores medianos da nossa língua, essa vírgula parece ser compreendida como uma pausa de ênfase, exatamente pela pregnância de ser a vírgula também um elemento de pausa na fala. $O$ ponto de interrogação ou o de exclamação usado no fluxo da frase, seguido de letra minúscula, sem a dupla função de entoação e finalização da frase, do tipo "Que boa notícia! tenho certeza que gostarei de vê-la.", que as gramáticas normativas chancelam, mas que pouca gente usa, na correspondência machadiana é frequente, porque de bom uso.

O uso escrito da língua tinha como modelo a língua literária e, secundariamente, o jornalismo, e este impregnado pela literatura, porque os mais importantes jornalistas daquele tempo eram literatos ou aspirantes. Um texto de uma época não tão recuada como a de Machado (seu manuscrito mais antigo tem 163 anos, e os mais recentes, 112) tem de ser compreendido no momento histórico daquela norma-padrão. Consultamos diversas gramáticas normativas do período, para compreender do ponto de vista morfossintático e mesmo semântico os usos presentes nas cartas. Além disso, há os recursos da Crítica Textual. Ela nos oferece um acervo eficiente de símbolos e sinais bem como a possibilidade das notas de pé de página, para resolver essas questões.

Como já disse, atualizamos a ortografia. Então as questões que se colocariam numa edição diplomática ou diplomático-interpretativa não se colocaram para nós. Por exemplo, todos sabemos que Machado usa preferencialmente "cousa", "doudo" e "dous". Há um ou outro caso em que o ditongo "oi" aparece nesses ambientes. As formas em uso no português brasileiro hoje são "coisa", "doido" e "dois". Outro exemplo: usamos "Novais" em lugar de "Novaes", tanto para Miguel e Faustino quanto para Carolina, Emília e Adelaide. Desenvolvemos as abreviaturas, segundo os critérios ecdóticos; à exceção das assinaturas abreviadas pelos missivistas no termo das cartas. De um modo geral, mantivemos a pontuação original dos missivistas, mesmo que parecesse ao olhar contemporâneo um desvio da norma-padrão 
da língua portuguesa escrita no Brasil hoje, salvo as exceções que na Nota Explicativa estão explicitadas.

As intervenções que fizemos na pontuação foram postas entre colchetes, como preconiza a Crítica Textual. Usamos para desambiguizar contextos, como por exemplo, nos longos parágrafos das cartas de Miguel de Novais; para acrescentar vocábulos claramente suprimidos no fluxo da escrita (por exemplo: "Eu conto [com] a sua benevolência.") etc. Nas partes ilegíveis e/ou danificadas, usamos os famosos (...). Além disso combinamos que as notas seriam personalizadas, já que fomos responsáveis separadamente por elas. Ao final de cada uma, temos as iniciais (IM) para Irene Moutinho, (SE) para Sílvia Eleutério e (SPR) para Sergio Paulo Rouanet.

Nas cartas, no plano da frase, não houve grandes problemas para a transcrição. Não alteramos a sintaxe de ordem nem a de colocação ou a de regência. Mantivemos tal e qual. A colocação dos clíticos nas cartas, de modo geral, mais especificamente dos pronomes oblíquos, segue a norma-padrão do Português Europeu, no uso da ênclise, próclise e da mesóclise. Observei nas frases negativas, sobretudo em Machado, a próclise do oblíquo movendo-se para antes do advérbio ("Marcela me não viu passar"). Há grande cuidado nas flexões verbais e nas concordâncias nominal e verbal. Dependendo das dimensões das cartas, há parágrafos longos, que exigem atenção na leitura, pois o referente podia estar bem distante do referido, dificultando a apreensão rápida do sentido. Há grandes interpolações e topicalizações, mas nada que a leitura não vença. Há também uma seleção vocabular bastante apurada, muitas palavras eruditas, citações latinas etc., consoante os padrões de cultura do tempo.

Nos primeiros doze anos da Correspondência (1857-1869), o uso do pronome de segunda pessoa do singular faz claramente a distinção entre intimidade e polidez. Depois de um determinado momento, o pronome de tratamento "você" alterna com o "tu". Não interferimos em nada disso. O que o missivista escreveu permanece nas cartas. $\mathrm{O}$ fato curioso é que, apesar do cuidado e do apuro, vez por outra fomos surpreendidas por usos linguísticos de caráter popular.

Como disse, o léxico é uma questão a que ficamos atentas. O que me pareceu mais complexo na Correspondência relaciona-se ao conteúdo das cartas propriamente; não de todas, é claro, há cartas triviais, pequenos bilhetes, do tipo "Encontro-te amanhã no teatro." Aquilo que eu, como leitora, precisei buscar fora do texto para compreendê-lo em profundidade é que me pareceu o desafio. Muitas vezes foi necessário descer aos detalhes para 
entender o que ali nas cartas subjazia: o vocabulário dos missivistas (por exemplo, palavras em desuso), a erudição de alguns deles, a referência a poetas, a dramaturgos ou a personalidades da época hoje quase inteiramente esquecidas. Há nas cartas palavras que refletem a forma de vida, o cotidiano, os usos e a polidez do século XIX, que para nós escapam. Muitas dessas palavras soam incompreensíveis às pessoas de hoje. O léxico do século XIX é uma questão para o pesquisador. Havia também as referências ao espaço urbano do Rio de Janeiro e do Brasil de então, que foi alterado ou não existe mais; havia as referências históricas, tanto da História Interna, quanto da História Externa; e os faits divers. Tudo isto é frequente nas cartas e precisou ser considerado em profundidade.

6. Como foi lidar com a correspondência ativa e também com a correspondência passiva de Machado? Ou seja, colocar lado a lado textos de um escritor consagrado e de outros não necessariamente de igual expressão? As diferenças de registro e de rigor textual eram muito grandes? Como vocês lidaram com essas diferenças?

Irene Moutinho: Na maioria dos casos, os interlocutores de Machado escreviam bem. Talvez menos no caso de algumas cartas, mais para o fim da vida dele, de pessoas desconhecidas. Mas, de maneira geral, os correspondentes se aproximavam do Machado devido ao seu campo de interesse comum, então existe certa uniformidade. É claro que há a singularidade da escrita do Machado, que ele imprime até num bilhete, e que faz com que você sinta que o texto vem de quem vem. Mas eu acho que as pessoas com quem ele se correspondeu todas tinham uma boa personalidade literária; não que tenham sido literatos, mas tiveram uma boa instrução literária. Um caso, por exemplo, é o do cunhado Miguel de Novais, que escrevia muito bem, como um bom português do século XIX, de uma família chegada às Letras. Ele não era, absolutamente, um estranho à forma literária. E há os estilos pessoais dos correspondentes, que não podemos menosprezar, só porque o outro era Machado. As pessoas escreviam corretamente.

Dirigiam-se a ele pessoas, em geral que tinham interesse em literatura e muito respeito por ele. Então havia sempre um chão comum. A não ser que fosse alguma coisa social, um convite, um cumprimento. Machado mesmo mantinha distintos registros, que iam desde um de muita cerimônia, passando por um de menos cerimônia, até um, muito restrito, de intimidade, e um mais 
raro ainda, de abertura afetiva. Desde muito moço, jornalista do Diário do Rio de Janeiro, ele se correspondia com os amigos que estavam em São Paulo, por exemplo, o Sizenando Nabuco, o Guimarães Júnior, que foi o primeiro correspondente dele, e que com dezessete anos já escrevia muito direitinho, as cartinhas são muito comoventes. Machado tinha vinte e quatro, vinte e cinco, publicara em livro apenas duas peças teatrais, mas já despontara como poeta, contista e cronista, e tinha aquela mão para a escrita feita pelo jornalismo, que é uma coisa impressionante.

Sílvia Eleutério: Trata-se de um universo humano muito largo. A correspondência ativa de Machado é muito vária, tanto na tipologia quanto no tom. Há cartas protocolares, confessionais, amorosas, funcionais, íntimas, panfletárias, políticas etc. E, dependendo, da intenção de Machado, a forma é extremamente cuidada, eivada de citações, como, por exemplo, a já citada carta aberta para José de Alencar, em resposta à apresentação do poeta Castro Alves e seu drama Gonzaga, quando Machado, aos 29 anos, se alça à posição de crítico chancelado pelo maior nome da literatura naquele momento.

É fato, há toda sorte de diferenças, tanto no plano das relações pessoais quanto no plano das relações sociais e profissionais. Na Correspondência, há missivistas com origens sociais e linguísticas diversas. Há interlocutores brasileiros, franceses, portugueses, luso-brasileiros, italianos, norteamericanos, argentinos etc. Há escritores, músicos de renome, historiadores, diplomatas, professores, estudantes, poetas, colegas de ministério, ministros de Estado, homens de negócios, juristas, dramaturgos, autoridades, instituições. Tudo compondo um vasto quadro de interlocutores. Há também os familiares, os amigos de juventude, os amigos da vida adulta, o círculo do Cosme Velho, os admiradores conhecidos e desconhecidos, os adversários e os inimigos.

Há entre seus interlocutores variados níveis de domínio da frase. Azurara, um mestre de meninos, que lhe escreve de Paquetá inicialmente como admirador, e depois se decepciona com a atitude do Machadinho, tem um padrão frasal e de competência escrita. O escritor português Eça de Queirós, que decididamente o interpela em 1878, tem outro; o historiador Capistrano de Abreu, cuja verve Machado tanto apreciava, tem outro. Constança de Alvim, dama da alta sociedade, insinuante, bem-educada e bemnascida, tem outro.

As "falas", digamos, têm muitos timbres, dependendo do que está em curso ali. Os escritores e intelectuais com os quais Machado se comunicava em 
geral dominavam bem os recursos da língua escrita: Euclides da Cunha, Aluísio Azevedo, Barão do Rio Branco, Oliveira Lima, Rodrigo Octavio, Ladislau Neto, Olavo Bilac, Raimundo Correia, Veríssimo, Salvador de Mendonça, Augusto de Lima e outros.

Machado tinha grande domínio no manejo da frase; há várias cartas em que é elegante, polido e formal. Já as do finalzinho da vida são mais descuidadas, refletindo o esforço e a dificuldade do transe. Observei também que os momentos mais significativos dependiam não só do assunto, mas da relação com o interlocutor e do seu estado de espírito. As duas cartas para Carolina são primorosas neste sentido. Algumas cartas para Magalhães de Azeredo contêm revelações muito íntimas do seu estado de espírito. No Tomo $\mathrm{IV}$, a perda da mulher é pungente. No Tomo $\mathrm{V}$, a tristeza profunda pela perda permanece como pano de fundo, mas na medida do possível MA reage dedicando-se à ABL e ao trabalho. Machado, apesar da dor, tinha vocação para vida e, resistindo, escreve ainda o Memorial e reedita alguns de seus livros.

As cartas para Mário de Alencar são reveladoras da intimidade de Machado, das sombras sobre seu espírito no fim de seus dias. Aliás a correspondência entre Machado e Mário de Alencar é um capítulo à parte. Ela merece um olhar aprofundado de quem deseja entender quem foi o homem por trás do escritor. Neste mesmo caminho, as cartas de Miguel de Novais revelam pelo jogo de espelhos aspectos da personalidade de Machado pouco conhecidos, e as para Magalhães de Azeredo também revelam muito dele.

7. Machado escreveu e publicou textos durante mais de cinquenta anos, período em que ajudou a definir, como escritor e como presidente da Academia, um novo padrão de escrita em língua portuguesa. Vocês identificaram mudanças significativas na escrita dele, ao longo do tempo e conforme o interlocutor?

Irene Moutinho: Como Capitu, o velho Machado já estava na casca do jovem Machado. Há textos do Machado muito jovem em que a fagulha de inteligência e estilo já está lá. É claro que existe um admirável aprimoramento, mas a escrita dele não muda muito, no sentido de uma evolução. Eu acho que há uma germinação, um aperfeiçoamento, não uma mudança de natureza. Inclusive, à medida que vai ganhando um repertório literário maior, ele continua escrevendo com os mesmos traços inconfundíveis. Nas primeiras colaborações para o jornal, nas primeiras crônicas, ele já está lá, inteiro. Há 
casos interessantíssimos, por exemplo, como uma notícia de janeiro ou fevereiro de 1869, na Semana Ilustrada, falando sobre as chuvas de Petrópolis, fazendo considerações sobre isso, e sem assinatura. Dos colaboradores da revista daquela época, quem é que subia para Petrópolis com mais frequência, para visitar a noiva, que morava lá? Era Machado, que ia ver Carolina. E, principalmente, o salzinho da notícia é machadiano. Então, não posso jurar de pé junto, mas é mil vezes mais provável que tenha sido ele a redigir essa nota, do que tenha sido outro.

Sílvia Eleutério: Acredito que a consciência da Língua Portuguesa do Brasil e da Literatura Brasileira foram um processo. Há, por exemplo, artigos de Alencar admitindo que usos da fala tipicamente brasileiros pudessem figurar na escrita; defendeu, por exemplo, o uso de "sentar na mesa" em lugar de "sentar-se à mesa", já comum àquela altura na língua falada. Lendo o "Ao correr da pena" (1854-1855), de Alencar, percebemos um jeito de fazer crônica que ecoará em Machado. É muito interessante isto. Machado foi um discípulo atento de Alencar; educou-se literariamente segundo os padrões do tempo, usando os recursos linguísticos disponíveis, mas de tal forma o fez que transformou a sua expressão singular num marco na literatura brasileira.

Machado e os seus correspondentes fizeram uso da língua portuguesa escrita do século XIX, em que a estrutura morfossintática padrão já era "sujeito + verbo + objeto", tal como hoje. Ainda não estava integralmente constituída a ideia de um Português Brasileiro, nem claramente consciente a separação entre língua falada e língua escrita, como agora. A questão que estava se colocando para os escritores e intelectuais do século XIX era a da afirmação da nacionalidade: uma Literatura Brasileira. No final do século XIX, início do XX, a reflexão sobre a sistematização da língua começa a surgir entre os confrades da ABL.

Acho que Machado, por ter realizado uma literatura absolutamente singular, usando os recursos disponíveis da língua àquela altura, estabeleceu um padrão de língua literária, que foi inspiração para muitos escritores. Claro que nas cartas não há uma intenção literária, Machado não está fazendo literatura, mas a sua discursividade, mesmo nos bilhetes mais simples, tem a sua sintomática. A gente vê os traços ali.

Como disse, as sintaxes de ordem, de regência e de colocação eram consoantes o padrão do Português Europeu. A colocação dos pronomes oblíquos, orientada pelo uso da ênclise e da mesóclise. A próclise do pronome oblíquo, muitas vezes movida para antes do advérbio. O cuidado nas flexões 
verbais e nas concordâncias nominal e verbal. Em cartas longas, muitos dos missivistas construíam parágrafos mais ou menos longos, em que o referente podia estar distante do referido. As regras de polidez, embora muito bem observadas, mudaram ao longo dos 51 anos documentados. Algumas vezes, como o controle do uso prescritivo da língua não era absoluto, encontramos claras evidências da língua falada manifestando-se na língua escrita.

8. Frequentemente, o trabalho de edição se confunde com o de interpretação, uma vez que a composição de um corpus de escritos acaba criando uma narrativa sobre a escritura deles. Quais narrativas surgiram, durante o processo de pesquisa e de edição, e como vocês lidaram com elas?

Irene Moutinho: As cartas funcionam muito, para mim, como peças de um puzzle. A partir das cartas, você volta ao Machado romancista, contista, cronista etc. e pensa "Ah, agora sim dá para entender melhor". Eu acho que a correspondência vai nos levando para dentro da obra dele com cada vez mais empenho e familiaridade, de modo que passamos a nos apossar um pouco daquele território, a nos apossar dele desde um prisma engajadíssimo. Sobre as notas, procurei sempre trazer nelas informações que realmente facilitassem a compreensão, que talvez desvendassem algum enigma. Sei que, por vezes, usei um adjetivo ou outro de encantamento, mas sempre apenas para qualificar alguma outra coisa substantiva que era dita. Para um editor, interpretação é uma coisa perigosíssima, e quanto mais você estiver atento exclusivamente ao que foi possível obter de concreto do escrito original, melhor. Esse rigor é muito importante. Num livro de crítica, tudo bem, mas esse não é o papel da anotação, a nota não é um terreno para se bordar em cima.

Sílvia Eleutério: Não sei se posso chamar de narrativa o que das cartas emergiu como prefiguração de uma época e dos personagens envolvidos. Há uma corrente no teatro que diz que a interpretação vem do texto, ou seja, todas as interpretações que um ator ou um diretor possam dar à produção criativa de uma peça emanam de alguma forma do próprio texto, seja na abordagem literal ou nas possibilidades de metáforas e metonímias que propuserem. Aquilo está ali como possibilidade, aliás, tanto para o bem quanto para o mal. 
O que das cartas emergiu é muito vasto, porque abrange todo tipo de relações, de fatos, de eventos.

Há o campo das relações pessoais, em que se pode observar como Machado se move entre os mais próximos. Mas, mesmo neste campo, há níveis e gradações de intimidade. Machado e Veríssimo tinham intimidade, mas era uma intimidade diferente da que Machado tinha com Mário Alencar, ou com Magalhães de Azeredo. A cada um desses relacionamentos corresponde uma faceta. Com Veríssimo, Machado às vezes era chistoso. Com Mário revelavase frágil e de guarda baixa. Com Azeredo, algumas vezes, foi profundamente confessional.

As cartas falam de aspectos pessoais de Machado de uma forma muito direta, dos dramas que viveu, das doenças pelas quais passou, das perdas que sofreu, das vitórias que obteve, das alegrias, das glórias, das lutas que teve de vencer, da função de medalhão que ocupou no imaginário do tempo.

Machado não é uma personalidade derramada. Sempre se disse que era tímido, reservado, que se escondia por trás da polidez. Este não é todo o Machado. Este é o Machado depois de 1879, depois de Memórias póstumas de Brás Cubas. Machadinho não era tão reservado, não era tímido e nem tão polido assim. Isto se observa lendo as cartas do período de 1857-1869. Ele polemiza, ridiculariza, bravateia etc. Estava abrindo caminho no jornalismo, é polêmico, mete-se em confusões. Por que se espantou tanto quando Lafaiete Rodrigues Pereira, o Labieno, em 1898, saiu em sua defesa contra o livro devastador de Sílvio Romero? Na juventude, por volta 1868, havia atacado e ridicularizado Lafaiete pelos jornais, a mando do presidente da província de Minas e dono do jornal onde trabalhava praticamente sozinho.

A respeito do livro de Sílvio Romero, aliás, as cartas de e para Mário de Alencar, e as cartas de e para Magalhães de Azeredo, deste fatídico ano de 1898, ano de grande adversidade para ele, mostram o quanto tudo aquilo foi difícil de enfrentar, apesar do apoio dos amigos e confrades.

Para mim, há um aspecto fundamental nas cartas de e para Machado elas recobrem 51 anos da História do Brasil, testemunham fatos decisivos, como por exemplo a mudança de regime político. Muitos missivistas foram figuras importantes tanto no Império quanto na República. De 1857 a 1889, Machado trocou cartas com ministros, políticos, escritores, financistas, figuras de proa do Império. Testemunhou a Lei do Ventre Livre, a Abolição da Escravidão. Trabalhou intensamente no Ministério em favor dos negros escravizados. De 1889 a 1908, surgem nas cartas os reflexos de muitos acontecimentos decisivos: o Período Floriano, o estado de sítio, a perseguição 
e o exílio de alguns amigos antiflorianistas, a Revolta da Armada, o período Prudente de Morais, com a sangrenta Guerra de Canudos e o pesado clima de perseguição que se foi instalando com o jacobinismo exaltado etc.

9. Vocês foram bastante parcimoniosas na anotação da correspondência. Para vocês, qual é o papel e qual deve ser o volume das notas explicativas, em edições de textos com tradição, como os de Machado de Assis? E de que maneira as novas tecnologias da informação modificaram a necessidade e a própria natureza das notas explicativas?

Irene Moutinho: Não houve um planejamento para as notas, elas foram surgindo espontaneamente. E chegaram a mais de quatro mil e quinhentas... Houve uma atitude muito receptiva do Rouanet, inclusive sabendo que nós duas tínhamos condutas bastante diferentes e que já estavam definidos os correspondentes pelos quais cada uma seria responsável. Mas não houve uma preocupação de natureza acadêmica, de modo que eu não posso dar regras ou normas sobre como se deve proceder sobre esse assunto.

Há notas que são fundamentais para a compreensão da carta. Por exemplo, um cartão que estava no Arquivo da Academia. É feito habilidosamente em um papel verde, com um par de florezinhas, preso por incisão de estilete, com uma única frase, uma saudação, em Sete de Setembro, e dá para ver assinado: Dr. Costa Ferraz. Quem é? E por que enviou esse cartão? Eu vim a descobrir, no livro do meu bisavô, Rodrigo Octavio, Minhas memórias dos outros, que há um capítulo sobre Costa Ferraz: que ele era um médico originalíssimo, e embalsamador inigualável. Fui investigando, investigando, e a partir daquela florzinha e daquelas duas linhas saiu quase um romance... Aquela habilidade de prender a florzinha no cartão, entre outras coisas, se explicava. Agora, o que teria feito um embalsamador se dirigir ao Machado...? Pensando bem, o cartão foi enviado pouco depois da publicação de Brás Cubas e talvez o Doutor estivesse querendo preservar o autor defunto ou defunto autor.

Sílvia Eleutério: É difícil esgotar todas as referências presentes num conjunto de 1179 documentos com a importância que esses têm. Sempre haverá algo ou que escapou ou a ser levantado ali. Na Correspondência, há notas de todo tipo: as que remetem a um dado histórico; as biográficas; as bibliográficas etc. As nossas notas são um pequeno guia ao leitor, para que as 
cartas possam ser lidas com mais conforto, contextualizando as referências julgadas fundamentais à compreensão do que ali era tratado. Com este propósito, fizemos 4518 notas, o que dá 903,6 notas por tomo, uma média razoável. Essa contextualização foi uma escolha e, como toda escolha, tem limites.

Decidimos circunscrever o aparato de notas por razões de tempo e quantidade de dados a pesquisar. Tínhamos um tempo delimitado para a editoração de cada um dos volumes. A quantidade de referências na maioria das cartas era grande. Muitas vezes Irene e eu ficávamos semanas pesquisando dados obscuros, ou difíceis de localizar, ou mesmo resistentes ao entendimento. Quando conseguíamos, ótimo. Depois de muita batalha, se não conseguíamos, céus, que chato! Esse era o limite.

Os dados que coletávamos precisavam quase sempre de entrar numa contextualização daquilo que estava sendo dito na carta, e tudo dependia da complexidade do que estava sendo dito. Outras vezes, além desta contextualização, eles se correlacionavam a outros dados de períodos anteriores, ou reapareciam em outras cartas daquele momento, ou noutras de períodos posteriores. Era preciso organizar esse tecido; então nós buscamos uma organicidade das notas. Isto, me parece, é fundamental numa edição de notas.

Não sei se há um volume quantitativo ideal de notas. Acho que deve haver um propósito quando se faz notas, que ampliem o entendimento do documento de que elas tratam. A Correspondência é uma obra, digamos, aberta, no sentido de que novas cartas ainda podem surgir, bem como as referências obscuras podem ser esclarecidas em razão do avanço das pesquisas da comunidade machadiana, das tecnologias e métodos de pesquisa, novos materiais e documentos e livros.

10. Para vocês, de que maneira a escrita privada de Machado de Assis (a correspondência) se relaciona com a sua escrita pública (todos os outros gêneros que praticou)? $\mathrm{E}$ de que maneira o contato com o homem, por meio das cartas, contribui para a compreensão do autor dos romances, contos, peças, poemas, crônicas, críticas?

Irene Moutinho: Uma produção ilumina a outra. Quanto mais eu leio o Machado escritor, mais encontro o Machado correspondente. O homem que escreve em particular, no seu estilo, não se distingue muito do escritor, a 
habilidade de se ocultar e de ao mesmo tempo se revelar é muito semelhante - mas para quem tiver a capacidade de enxergar... Uma coisa que eu acho muito interessante é o arquivo conservado por Machado, que veio logo depois da morte dele para Academia, onde já se achava a sua correspondência institucional, como presidente. Somente noventa anos mais tarde chegaram outros documentos, pertencentes a D. Laura, sobrinha de Carolina e herdeira dele, cartas, rascunhos, anotações. O conjunto, tanto o original da Academia quanto o que veio depois através de comodato com a UFRJ, revela algo apaixonante: Machado guardou muito, não se pode dizer que tudo, mas muito da sua correspondência. Agora, como? Foi um Machado mocinho que guardou as cartas juvenis de um Guimarães Júnior, que estava em São Paulo, com dezoito anos, fazendo os preparatórios para a Faculdade de Direito, e escrevia para ele, Machado, com vinte e quatro para vinte e cinco anos, na redação do Diário do Rio de Janeiro. Ele guardou todas as cartas, guardou também as do Sizenando, sobretudo essas mais antigas. Quem era o Machado, nessa época? Era um rapaz que não tinha uma casa, não tinha um escritório, não tinha um mobiliário, vivia não se sabe bem como, especula-se que em quartos de pensão, em sobrados do Centro do Rio, onde ele possivelmente dividia quarto e provavelmente tinha apenas uma cama, uma mesa, algo assim. Isso mostra que ele se aferrou, dando um significado afetivo extraordinário a elas, às cartas que recebeu muito jovem, sem previsão alguma do seu próprio futuro ou do futuro do seu correspondente. Que ele fosse guardar uma carta, mais tarde, de um Joaquim Nabuco, ninguém tem dúvida, porque ele tinha onde guardar, tinha por que guardar, tinha todos os motivos. Mas aquilo que ele conservou da juventude é admirável, porque ele e os seus correspondentes estavam cada um escrevendo a sua própria história de vida, e um rapaz sem dinheiro, como ele, em 1860, não tinha motivo para conservar tudo o que recebia, salvo as suas razões pessoais, o seu apego afetivo. Aquela caixa de cartas, aquele bauzinho, era o seu tesouro.

Sílvia Eleutério: A intertextualidade é uma presença forte nas cartas. Este é um cruzamento que valeria a pena ser feito em minúcia. Há coisas muito interessantes, que nos permitem uma compreensão alargada do homem e do literato Machado de Assis. Vou dar um exemplo. Machado, segundo seus biógrafos, não falava aos amigos de seus escritos em andamento. $\mathrm{Na}$ Correspondência, no entanto, observamos momentos em que tal atitude não existiu. 
Miguel de Novais, seu cunhado, depois que casou com a viúva do Conde de São Mamede (1876), Joana Maria Ferreira, voltou a viver em Portugal (1881) e foi um interlocutor privilegiado. Embora os originais de Machado para Miguel não estejam disponíveis, as cartas de Miguel permitem entrever um diálogo sem reservas a respeito de sua produção literária e de política brasileira. Nas cartas da década de 1880, em que a correspondência entre ambos foi frequente, Miguel faz comentários longos a respeito dos contos de História sem data, de Papéis avulsos, de Várias histórias, do romance Quincas Borba. Em seus comentários, revela uma intimidade e um interesse grande nas obras do cunhado, inclusive incentivando-o a publicá-las em Portugal. Lendo as cartas de Miguel de Novais percebemos o quanto Machado se comunicava com este cunhado de temperamento alegre e bem-humorado. Frequentemente, Miguel faz referência ao que Machado lhe teria dito em cartas que lhe enviou, constituindo comentários preciosos e esclarecedores a respeito do escritor. Miguel dizia-lhe com sinceridade de suas impressões de leitor típico; não era comprometido por uma atitude reverente diante, a essa altura, do incensado mestre do romance e do conto brasileiros. Fazia suas observações com grande acuidade, outras vezes um tanto ingenuamente, mas quase sempre com sensibilidade e independência consideráveis.

\section{Referências:}

ASSIS, Machado de.Correspondência de Machado de Assis, tomo II - 1870-1889. Organização de Sergio Paulo Rouanet, Irene Moutinho e Sílvia Eleutério. Rio de Janeiro: ABL, 2009.

DIMAS, Antonio. Anotações sobre a correspondência de Machado de Assis. Machado Assis em linha, São Paulo, v.10 n.21, p. 158-178, agosto 2017. $<$ http://dx.doi.org/10.1590/1983-6821201710219>.

MORAES, Marcos Antonio de. Epistolografia de Machado de Assis: escrita de si e testemunhos de criação literária. Machado Assis em linha, São Paulo, v.4 n.7, p. 88-111, junho 2011. <http://machadodeassis.net/revista/numero07/rev_num07_artigo06.pdf>. 
MARCELO DIEGO é professor adjunto de Literatura Comparada na Universidade Federal do Rio de Janeiro e membro do Grupo de Pesquisa / CNPq "Ficção de Machado de Assis: sistema poético e contexto". (D)https://orcid.org/0000-0001-8590-5009 E-mail: marcelodiego@letras.ufrj.br

Recebido: 04.02.2019

Aprovado: 01.03.2020 